\title{
Determinación inmunohistoquímica de CD1 17/c-kit en el GIST (tumor estromal gastrointestinal)
}

\author{
M. F. Fresno Forcelledo
}

\section{Introducción}

Los tumores mesenquimales del tracto gastrointestinal más frecuentes corresponden a los llamados GIST o tumores estromales gastrointestinales. Reconocidos como tales hace relativamente poco tiempo', con anterioridad se denominaban leiomiomas, leiomioblastomas y leiomiosarcomas y con menor frecuencia, proliferaciones de naturaleza nerviosa. En los últimos años se ha producido un considerable avance en la comprensión de su histogénesis, biología y mecanismos moleculares alterados y que han supuesto un considerable avance para el diagnóstico, pronóstico y posibilidades terapéuticas.

Los GIST se localizan preferentemente en estómago e intestino delgado, aunque pueden desarrollarse en cualquier localización del tracto gastrointestinal e incluso extragas trointestinal. Con el empleo rutinario de las técnicas inmunohistoquímicas, en los primeros años ochenta se observó que los presumiblemente leiomiomas/leiomiosarcomas gastrointestinales habitualmente no expresaban marcadores de músculo liso (actinas y desmina) y sí, en cambio, era casi constante la expresión de otras proteínas como CD11 $7^{2-4}$ y en una alta proporción de casos $\mathrm{CD} 34^{5,6}$. Todo ello planteó una reconsideración de su histogénesis. Este perfil inmunohistoquímico de las células tumorales en el GIST es similar a las llamadas células intersticiales de Cajal que juegan un papel importante en el control del peristaltismo grastrointestinal, por lo que hoy se admite como histogénesis más probable para los GISTs la célula intersticial de Cajal7,8.

La oncoproteína CD1 17/c-kit se ha convertido, por tanto, en un marcador imprescindible en el diagnóstico de estos tumores. Estudiaremos las características de este marcador, su perfil de expresión, sistemas de determinación y cuantificación.

Servicio de Anatomía Patológica I

Hospital Central Universitario de Asturias

Oviedo

\section{CD117/c-kit}

KIT (c-kit) es una proteína transmembrana (glicoproteína) de $145 \mathrm{KDa}$. Funciona como un receptor con actividad tirosin quinasa. Es el homólogo celular normal del producto del oncogén vírico v-kit y pertenece a la subclase III de la familia de receptores tirosin quinasa. CD117 es un epítopo localizado en el dominio extracelular del receptor. KIT es estructuralmente similar a otros receptores con actividad tirosin quinasa con posibilidades oncológicas, como el receptor del factor de crecimiento derivado de plaquetas (PDGFRs) A y B, CSFIR (factor estimulante de colonias) y otros. El receptor posee un dominio extracelular con cinco regiones de tipo lg-like, una región única transmembrana y un dominio intracitoplasmático con actividad tirosin quinasa?.

El gen c-kit se localiza en el cromosoma 4 (4q11-12), próximo al gen del receptor de crecimiento epidérmico (EGFR) y también del receptor del factor de crecimiento derivado de plaquetas (PDGFR).

El ligando para KIT se conoce como SCF(stem cell factor). La activación del receptor se produce como consecuencia de un proceso de homodimerización. Este proceso provoca una serie de cambios estructurales en el receptor que determinan una activación del dominio con actividad quinasa de KIT y fosforilación de numerosas proteínas ${ }^{10}$. El resultado final de la activación es la génesis de una serie de señales que actúan sobre procesos cruciales en la tumorogénesis como proliferación celular, adhesión, apoptosis y diferenciación.

Se ha observado una expresión alta de KIT en células hematopoyéticas progenitoras, células cebadas, melanocitos, células germinales y en las ya comentadas células intersticiales de Caja ${ }^{11,12}$. Estas células forman una red localizada en el plexo de Auerbach regulando la comunicación entre neuronas y fibras musculares lisas, necesarias para regular los movimientos peristálticos intestinales. Probablemente la célula progenitora tendría la capacidad de diferenciarse hacia una célula muscular lisa o intersticial de Cajal. La expresión de KIT sería necesaria para la diferenciación y proliferación de células precursoras hacia células intersticiales de Cajal.

Además de los criterios clásicos que diferencian los tumores benignos de los malignos (tamaño, mitosis y localización), se intenta buscar nuevos marcadores, tanto pronósticos de comportamiento biológico, especialmente en tumores pequeños con escaso número de mitosis y poder metastatizante, como predictivos de respuesta al tratamiento. Muchos de los estudios se centran en alteraciones mutacionales en el gen KIT y 
en otras alteraciones cromosómicas, especialmente en pérdidas de cromosomas 14 y/o 22. Las mutaciones pueden afectar a diferentes exones $(11,9$ y 13). Las mutaciones en el exon $11^{2}$ se asociarían con una mejor respuesta al tratamiento $y$ en el exon 9 con una mayor agresividad. Los resultados son preliminares $y$, en muchas ocasiones, discordantes ${ }^{13-15}$.

\section{Determinación inmunohistoquímica de CD117/c-kit}

Actualmente existen en el mercado varios anticuerpos tanto poli como monoclonales que son capaces de detectar el epítopo CD 17 localizado en el dominio externo de la oncoproteína KIT.

Tres de estos anticuerpos son policlonales: pAb A4502 (DakoCytomation), pAb scl68 (Santa Cruz) y pAb 7902936 (Novocastra) y uno es monoclonal: mAb RB1518 (Neomarkers). Estos anticuerpos fueron testados por un laboratorio privado (NordiQC) que remitió diferentes preparaciones sin teñir a un total de 56 laboratorios. En las evaluaciones finales, un total de 20 laboratorios (36\%) lograron los mejores resultados, $15(27 \%)$ resultados buenos, $14(25 \%)$ regulares y $7(13 \%)$ resultados pobres. En este control de calidad, el anticuerpo utilizado con mejores resultados fue pAb4502 (DakoCytomation) en combinación con una recuperación antigénica mediante calor. La dilución utilizada más frecuentemente fue entre 1:200.-1:500. En esta evaluación las causas mas frecuentes de tinción insuficiente fueron:

1. Elección inapropiada del anticuerpo primario;

2. Concentración excesivamente baja del anticuerpo primario (especialmente en aquellos casos en que se utilizó un protocolo con escasa sensibilidad);

3. Excesiva concentración del anticuerpo primario;

4. Escasa recuperación antigénica.

El patrón de tinción es citoplasmático difuso con una acentuación en la membrana.

La mayoría de los autores refieren una positividad constante en los tumores GIST, aunque otros como Madeiros ${ }^{16}$ admiten que probablemente pueda existir un pequeño número de tumores negativos, no siendo, por tanto, un requisito imprescindible la positividad para CD1 17 para diagnosticar un GIST. Además de que puedan existir GIST con ausencia de mutaciones y/o de sobreexpresión de c-kit, las causas de una negatividad inmunohistoquímica para CD1 17 pueda obedecer a otros motivos, como escasez de representación tumoral en biopsias endoscópicas y en tumores con distribución irregular de la oncoproteína, pérdida de antigenicidad por manipulación inadecuada de la muestra o defecto en el procesamiento técnico o alteraciones postratamiento.

Aunque puede existir cierta variabilidad en el patrón de tinción, la mayoría de los GIST muestran una positividad citoplasmática intensa y difusa. En más del $50 \%$ de los casos es evidente un patrón característico llamado golgiano, caracterizado por un refuerzo a modo de gránulo paranuclear (dot-like) y que coexiste con el patrón citoplasmático difuso habitualmente pero que, en ocasiones, puede ser exclusivo ${ }^{17}$. Este tipo de patrón de tinción podría relacionarse, según algunos autores, con un tipo concreto de mutación del protoncogén c-kit.
Algunos tumores GIST pueden mostrar una positividad no difusa sino limitada a un escaso porcentaje de células tumorales (5-20\%), lo cual puede justificar algunos casos inmunohistoquímicamente negativos como hemos mencionado previamente ${ }^{17}$.

La variedad epitelioide de los GISTs muestra una tinción menos intensa que la fusocelular. Los tumores de músculo liso (positividad para actina de músculo liso y desmina) y los schwanoma (positividad para proteína S100) son negativos para CD1 17. El dermatofibrosarcoma protuberans, hemangiopericitoma, el liposarcoma esclerosante bien diferenciado, el angiosarcoma y el sarcoma de Kaposi pueden ser positivos focalmente. Otros tumores que pueden ser positivos con CD117 son melanomas y sarcoma de células claras (un tercio de los casos), carcinoma pulmonar de célula pequeña, sarcoma de Ewing, linfoma anaplásico de célula grande, seminoma, leucemia mieloide aguda, gliomas y carcinoma endometrial.

La validez de nuestra técnica inmunohistoquímica ha de estar refrendada por el empleo de controles adecuados positivos y negativos. En este sentido, la positividad constante para las células estromales cebadas sirve como un control interno perfecto.

Además de la expresión de CD117/c-kit, en los tumores GIST se observa positividad para CD34 entre un 60-70\% de los casos, actina de músculo liso (30-40\%) y alrededor de un $5 \%$ para proteína $\mathbf{S 1 0 0}$. Ninguno de estos marcadores es específico para los GIST. Sólo un pequeño porcentaje de casos (1-2\%) presentan positividad para la desmina de forma focal. La inmunotinción para CD34 es más frecuente en tumores de colon y esófago y para actina de músculo liso en tumores de intestino delgado.

En nuestro Servicio hemos revisado nuestros casos de GIST desde 1995 y hemos seleccionado 21 tumores (Tabla I). Realizamos un estudio inmunohistoquímico utilizando un

TABLA I

\begin{tabular}{lccccc}
\hline Caso & CD117 & CD34 & Actina ML & Desmina & PS100 \\
\hline 1 & + & - & + focal & - & - \\
2 & + & - & - & - & - \\
3 & - & - & - & - & - \\
4 & - & + & - & - & - \\
5 & + & + & + & - & - \\
6 & + & + & - & - & - \\
7 & + & + & - & - & - \\
8 & + & + & - & - & - \\
9 & + & + & + & - & - \\
10 & + & - & - & - & - \\
11 & - & + focal & - & - & - \\
12 & + & + & - & - & - \\
13 & + & - & - & - & - \\
14 & + & - & - & - & - \\
15 & + & + & - & - & - \\
16 & + & + & + focal & - & - \\
17 & + & + & - & - & - \\
18 & + & + & - & - & - \\
19 & + & + & - & - & - \\
20 & - & - & - & - & - \\
21 & + focal & + focal & - & - & - \\
\hline & & & & & - \\
\hline
\end{tabular}




\section{F. Fresno Forcelledo}

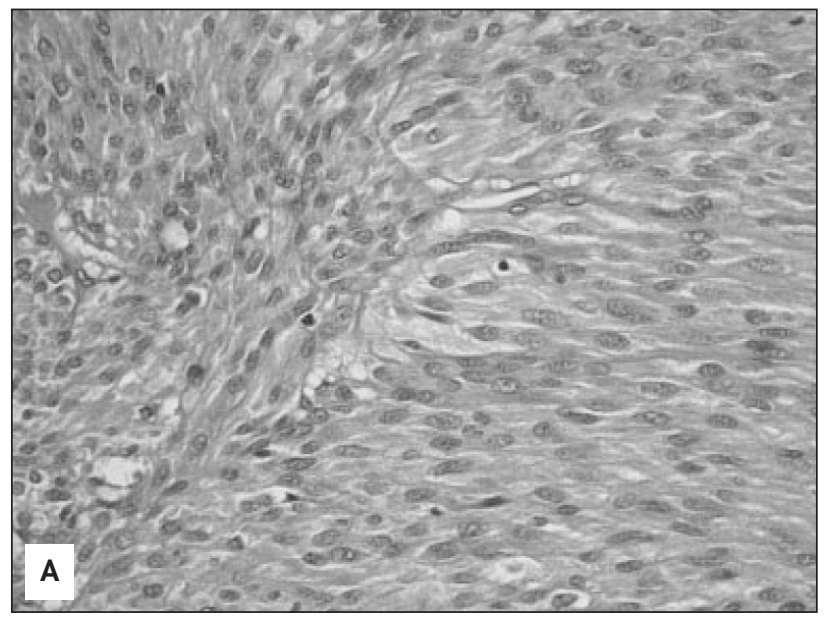

Fig. 1. A) Aspecto microscópico típico.

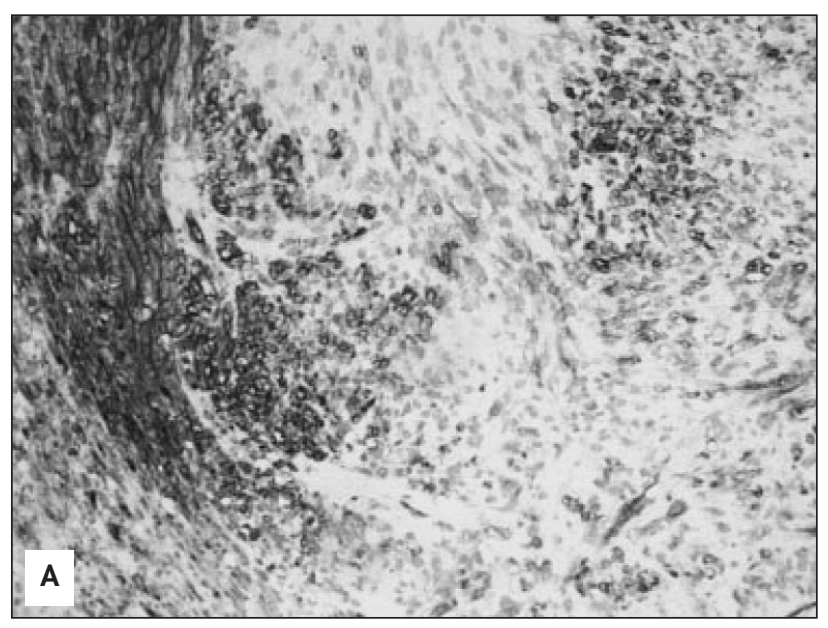

Fig. 2. A) Tinción irregular. Areas intensamente teñidas alternan con otras no teñidas.

pequeño panel con los siguientes marcadores: CD117 (DakoCytomation), CD34 (clon QBEND/10; Biogenex), Actina de músculo liso (clon 1A4; Dako), desmina (clon D-33; Dako) y proteína S100 policlonal (clon S-2019; Dako).

El protocolo utilizado para la determinación de CD117 fue el siguiente:

Anticuerpo: pAb A4505 (DakoCytomation) a dilución 1:200. El material se procesó de forma habitual con fijación en formaldehído e inclusión en parafina. Se realizaron cortes a 5 micras. Se utilizó como recuperador antigénico el calor mediante olla a presión en una solución de buffer-citrato a pH 6,5 durante 4 minutos. El tiempo de incubación con el anticuerpo primario fue de 30 minutos a temperatura ambiente. El procedimiento de visualización utilizado fue el Envision. Se usó diaminobencidina como cromógeno y contratinción con hematoxilina. En el resto de anticuerpos, excepto con la proteína $\mathrm{S100}$, se utilizó la olla con buffer citrato a pH 6.5 durante 4 minutos como recuperador de antígeno. Para la proteína S100 se utilizó proteinasa K durante $10 \mathrm{mi}$ nutos.

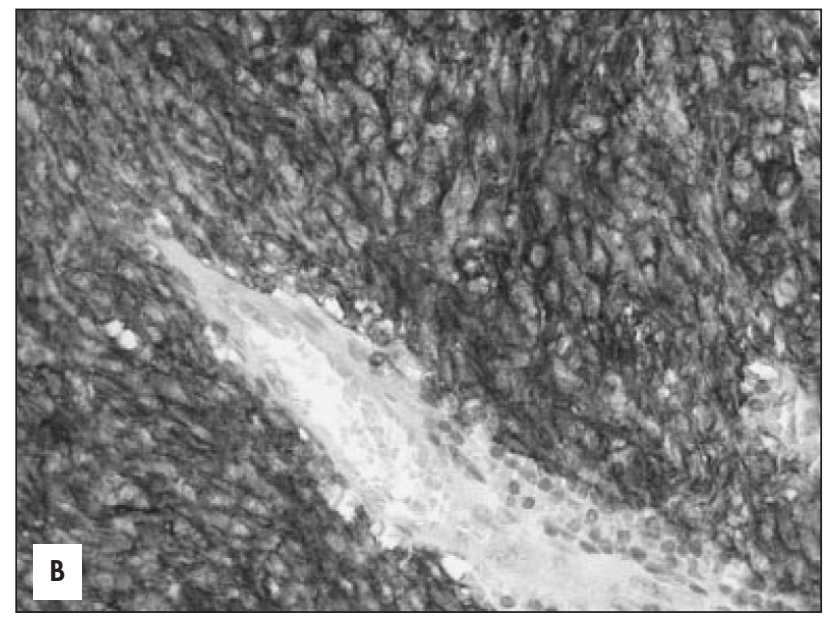

Fig. 1. B) CD1 17. Intenso y difuso patrón de tinción citoplasmático con refuerzo de la membrana celular.

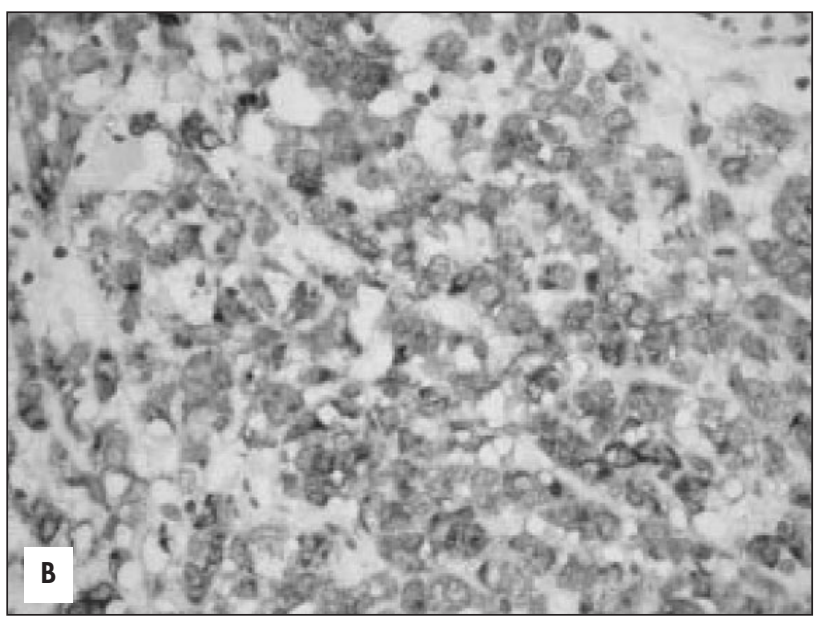

Fig. 2. B) Refuerzo paranuclear de la tinción con CD1 17/c-kit.

Observamos los siguientes resultados: 17 de los 21 casos fueron positivos para CD1 17 (80.91\%) (Figs. 1 y 2). La positividad, excepto en un caso, fue difusa. CD34 fue positivo en 14 casos $(66,6 \%)$. Actina de músculo liso 4 casos (2 focal) $(19,04 \%)$. La desmina y la proteína S100 fueron negativas en todos los casos. Dos de los casos que fueron negativo para CD117 mostraron positividad para CD34, uno de forma focal.

\section{Conclusión}

Como en otros campos de la patología tumoral, la inmunohistoquímica ha propiciado una herramienta poderosa para el diagnóstico y la histogénesis de los GIST. Aunque un altísimo porcentaje de casos son positivos para CD117, es posible, y en nuestra experiencia ha sido así, algunos tumores, morfológicamente similares, pueden ser negativos debido a diversos motivos. Una estandarización de la técnica, como ha ocurrido con otros marcadores de dianas terapéuticas sería de gran ayuda en la determinación de CD1 17. 


\section{Bibliografía}

1. Mazur MT, Clark HB. Gastric stromal tumors: reappraisal of histogenesis. Am J Surg Pathol 1983; 7:507-19.

2. Hirota S, Isazaki K, Moriyama $Y$ et al: Gain-of-function mutación of c-kit in human gastrointestinal stromal tumors. Science $1998 ; 279: 577-80$.

3. Sarlomo-Rikala M, Kovatich AJ, Barusevicius A, et al. CD 117 : a sensitive marker for gastrointestinal stromal tumors that is more specific than CD34. Mod Pathol 1998; 11:728-34.

4. Kindblom LG, Remoti HE, Aldenborg $F$, et al. gastrointestinal pacemaker cell tumor (GIPACT): Gastrointestinal stromal tumors show phenotypic characteristics of the interstitial cell of Cajal. Am J Pathol 1998; 152:159-1269.

5. Miettinen M, Virolainen M, Sarlomo-Rikala M. Gastrointestinal stromal tumors: value of CD34 antigen in their identification and separation from true leiomyomas and schwannomas. Am J Surg Pathol 1995; 19:207-16.

6. Mikhael Al, Bacchi CE, Zarbo RJ, et al. CD34 expression in stromal tumors of the gastrointestinal tract. Appl Immunohistochem 1994; 2:89-93.

7. Sircar K, Hewlett BR, Huizinga JD, et al. Interstitical cells of Cajal as precursors of gastrointestinal etromal tumors. Am J Surg Pathol 1999; 23:377-89.

8. Robinson TL, Sircar K, Hewlett BR et al. Gastrointestinal stromal tumors may originate from a subset of CD34-positive interstitial cells of Cajal. Am J. Pathol. 2000; 156:1 157-63.

9. Heinrich MC, Rubin BP, Longley BJ, Fletcher JA. Biology and genetic aspects of gastrointestinal stromal tumors: KIT activa- tion and cytogenetic alterations. Hum Pathol 2002; 33:48495.

10. Ashman LK. The biology of stem cell factor and its receptor ckit. Int J Biochem Cell Biol 1999; 31:1037-51.

11. Tsuura $Y$, Hiraki $H$, Watanabe $K$ et al. preferential localization of c-kit product in tissue mast cell, basal cell of the skin, epithelial cell of breast, small cell lung carcinoma, and seminoma/ dysgerminoma in humans: immunohistochemical study of formalin-fixed, paraffin-embedded tissues. Virchows Arch 1994; 424:131-41.

12. Maeda H, Yamagata S, Nishikawa S, et al. Requirement of ckit for development of intestinal pacemaker system. Development 1992; 116:369-74.

13. Lux ML, Rubin BP, Biase TL, et al. Extracellular and kinasa domain mutations in gastrointestinal stromal tumors. Am J Pathol 2000; 156:791-5.

14. Lasota J, Jasinski M, Sarlomo-Rikala M, et al. Mutations in exon 11 of c-kit occur preferentially in malignant versus benign gastrointestinal stromal tumors and do not occur in leiomyomas or leiomysarcomas. Am J Pathol 1999; 154:53-60.

15. Ernst SI, Hubbs AE, Przygodzki RM, et al. KIT mutation portends poor prognosis in gastrointestinal stromal/smooth muscle tumors. Lab Invest 1998; 78:1633-6.

16. Madeiros F, Duensing A, Hornick JL, et al. KIT negative gastrointestinal stroma tumors. Hum Pathol 2003; 16:28A.

17. Fletcher CDM, Berman JJ, Gorstein F, et al. Diagnosis of gastrointestinal stromal tumors: a consensus approach. Human Pathol 2002; 33:459-65. 